\title{
Perinatal, neonatal, and rearing period mortality of dairy calves and replacement heifers in France
}

\author{
D. Raboisson, ${ }^{*} \dagger^{1}$ F. Delor, ${ }^{*} E$. Cahuzac, $\dagger$ C. Gendre, $\dagger$ P. Sans, ${ }^{*}$ and G. Allaire \\ *Université de Toulouse, Ecole Nationale Vétérinaire, 23 chemin des Capelles, F- 31076 Toulouse Cedex 3, France \\ †Observatoire des programmes communautaires de développement rural, INRA Toulouse, chemin de Borde-Rouge, F- 31326 Auzeville, France
}

\begin{abstract}
Dairy calf and replacement heifer mortality in France was assessed by calculating mortality rates at 0 to 2 $\mathrm{d}$ (calves), $3 \mathrm{~d}$ to $1 \mathrm{mo}$ (calves and heifers), 1 to $6 \mathrm{mo}$ of age, and 6 mo of age to first calving (heifers) using the national identification database. Between birth and 2-d-old, 261,000 and 251,000 of the 3.56 and 3.43 million calves born in 2005 and 2006, respectively, died. The overall 0 - to 2 -d-old calf mortality rate was around $6.7 \%$, which is similar to the low range of values reported in the literature. Among the 2.38 and 2.39 million calf-month, 139,000 and 133,000 died between $3 \mathrm{~d}$ and 1 mo of age in 2005 and 2006, respectively. Among the $3 \mathrm{~d}$ to $1 \mathrm{~m}$ of age group, dairy calf mortality rate was around $5.7 \%$. Such a rate has not been reported previously because of the great differences in age classes between studies. For the 0- to 2-d-old and 3-d- to 1-moold calves, annual mortality was zero on 26 and $44 \%$ of the farms, respectively. Calf mortality during the first month of life increased in winter (to $12-17 \%$ ) and decreased in summer (to $8-12 \%$ ), with a small peak in June or July. Mortality during the first month of life is higher in males than in females, with a mortality odds ratio of 1.20 (and 95\% confidence interval of 1.19-1.21). Such a difference is also found within the noncrossed or beef-crossed calf subpopulations. Disregarding the sex, the mortality of beef-crossed calves is slightly less than that of noncrossed dairy calves, with a mortality odds ratio of 0.98 (and $95 \%$ confidence interval of $0.98-0.99$ ) before 1 mo of age. In heifers, around 51,000, 35,000, and 40,900 out of the 1.2 million 3 -d- to 1 -mo-old, 1.1 million 1- to 6-mo-old, and 950,000 6-mo-old to first calving heifers died, respectively. The respective mortality rates were $4.5,3.1$, and $4.1 \%$; these rates are similar to the low range of values previously published. The proportions of farms with no heifer mortality during a year were higher than for calves, between 60 and $70 \%$. The mortality probability for heifers was very high for
\end{abstract}

Received July 31, 2012.

Accepted January 22, 2013.

${ }^{1}$ Corresponding author: d.raboisson@envt.fr the first day of life (95\% survival between 2-30 d of age), then decreased during the first year of life and became constant up to around 3 yr of age ( $88 \%$ survival at 36 mo of age). The risk of mortality is higher in Montbéliarde and Normande heifers compared with Holstein. In conclusion, and beyond the average mortality rates, farmers and farm advisors should keep in mind the broad range of mortality values, which shows that very low mortality $(1-2 \%)$ can be achieved, even in animals with a known high risk of mortality, such as beef-crossed dairy calves.

Key word: dairy calf mortality, dairy heifer mortality, sex, breed

\section{INTRODUCTION}

Calf mortality represents economic losses to the dairy industry due to delayed genetic progress, fewer replacements available for voluntary culling of the lactating herd, and increased cost of replacement. In the United States, the annual economic damage resulting from stillborn and loss of calves is reported to be about $\$ 125$ million (Meyer et al., 2001). The total costs of calf and heifer mortality are probably underestimated; for instance, the total costs of stillbirth far exceed the value of the calves and must include the higher risk of death and reproductive complications in the dams (Ortiz-Pelaez et al., 2008). Because of the decrease in dairy cow numbers and the increase in calf mortality, the availability of male dairy calves for the fattening industry has tended to decrease. This represents a future danger for that sector, particularly in countries with an important veal calf industry, such as France (Sarzeaud et al., 2008).

Moreover, calf and heifer mortality is considered a welfare issue, and calf mortality has been identified as one of the most important indicators of dairy farm health status (Ortiz-Pelaez et al., 2008). The continuous increase in calf and heifer mortality reported in many countries during the last decade suggests that the economic and welfare stakes related to the mortality of young cattle are also increasing (Meyer et al., 2001; Berglund et al., 2003; Steinbock et al., 2003). 
An accurate estimation of calf and heifer mortality is important to define the political and financial priorities for the value chain and cattle health programs. Numerous observational studies have been carried out to document mortality rates in calves and heifers (Meyer et al., 2001; Bicalho et al., 2007; Lombard et al., 2007; Johanson et al., 2011), to define the causes of the deaths (Agerholm et al., 1993; Menzies et al., 1996; Svensson et al., 2006), and to identify some risk factors of young cattle mortality (Chassagne et al., 1999; Svensson et al., 2006; Stull et al., 2008; Gundelach et al., 2009). Except for stillbirth, the classes of age used in the mortality studies differ considerably between studies, although 1 or 2 main causes of mortality can be determined when precise and narrow classes are built (Svensson et al., 2006; Gulliksen et al., 2009). The use of exhaustive databases allows an accurate estimation of mortality according to classes of age. It also prevents selection bias linked to the exclusion of nonmember farms (when using Milk Control Program databases for instance) or restricted to some geographical areas.

The aim of this study was to describe dairy calf and replacement heifer mortality using a data set which included all French herds for 2 years. The relative risk of mortality for some characteristics of the animals was also quantified.

\section{MATERIALS AND METHODS}

\section{Data Sets}

Data concerning all cattle and herds were extracted using MySQL-software (MySQL, version 5.0, Redwood City, CA). All data were geo-located at the municipal level. The municipalities were gathered into dairy production areas as previously described (Raboisson et al., 2011). The detailed characteristics of the National Bovine Identification Database have already been described (Raboisson et al., 2011). Briefly, it contains routine records of individual data for farms and animals. Animals were sorted and associated with a dairy, beef (cow-calf), or fattening (bulls, steers, or veal calves) herd within each farm.

\section{Mortality Rates}

The mortality rates were calculated yearly (for 2005 and 2006) for each class of animals and within each herd. The 0 to $2 \mathrm{~d}$ mortality rate (i.e., the number of deaths between birth and $2 \mathrm{~d}$ of age divided by the number of born calves) was calculated for the pure breed (noncrossed) and the beef-crossed (dairy dam and beef sire or beef AI) dairy calves. The 3-d- to 1-mo-old calf, the 3-d- to 1-mo-old heifer, the 1- to 6-mo-old heifer, and the 6-mo-old to first calving heifer mortality rates were the number of deaths during the respective period divided by the number of calf-month, heifer-month, heifer-5 month, and heifer-year, respectively. The number of animal-period was calculated with the time at risk for each class of animals. For instance, one calf staying alive for one month accounted for 1 calf-mo, but if it stayed alive for $2 \mathrm{wk}$ it only accounted for 0.5 calf-mo. For the $3 \mathrm{~d}$ to 1 mo calf mortality, noncrossed and beef-crossed calves were also distinguished and the mortality rates were also calculated with the number of calves present at $2 \mathrm{~d}$ of age, in addition to calculations made with the number of calf-mo. Because of the small to moderate average herd size of French dairy cattle farms (Raboisson et al., 2011), the mortality rates were deleted from the database (no value) when the denominator was under 5 units (the unit of the denominator was dependent on the class of animal). This prevented overestimation of the mortality rates related to a small herd or to a herd with a low number of animals in one class (a large herd with few beef-crossed dairy calves, for instance).

\section{Statistical Analysis}

Data were analyzed using $\mathrm{R}$ (version 2.10.1, The R Foundation for Statistical Computing, Vienna, Austria). The descriptive statistics for the numbers of deaths, animals at risk (animals at a given age or animal-period), and farms with and without mortality were performed. The mean French mortality rate per class of animals was calculated including and excluding mortality rates equal to zero by averaging the herd-level mortality rates. The need for inclusion or exclusion of the zero values was suggested by the high proportion of farms with no mortality (for one class of animals) in France. The overall national number of deaths over the overall national number of animals at risk was also calculated.

A survival analysis was then performed for all animals born in 2005 and 2006, distinguishing the age classes of the animals, the characteristics of the calves (sex and breed) and the dairy production areas. The survival probability was obtained by calculating the KaplanMeier estimator (package survival of $\mathrm{R}$ ), disregarding the fact that a dependence on herd might exist. For all calves except heifers, the Kaplan-Meier estimator was calculated from birth to exit, or to $30 \mathrm{~d}$ of age if exit occurred after that. For heifers, the survival estimator was calculated from the age of $2 \mathrm{~d}$ and up to $30 \mathrm{~d}$ of age or the first calving, disregarding the movements between farms during this period. The dairy production area used for the survival analysis was the birth place for calves and heifers between birth and $30 \mathrm{~d}$ of age. It 
was the first calving place for heifers between $2 \mathrm{~d}$ of age and the first calving. The odds ratios of mortality were then calculated for the different groups of animals ( $R$ package epitools).

\section{RESULTS}

The descriptive statistics and mortality rates are reported in Tables 1, 2, and 3. The number of dairy farms and the number of calves and heifers born decreased slightly between 2005 and 2006. The mortality rates were however very similar among the 2 years, whatever the classes of animals considered. Within a year and a class of age, the results were also very similar between the whole population and the non-crossed calves, in relation to the high percentage of farms and animals in the non-crossed class $(>80 \%)$.

The percentage of farms with zero mortality was around 26 and $46 \%$ for the 0 - to 2 -d-old and 3 -d- to 1-mo-old calves, respectively; it was higher for beefcrossed dairy calves as well as for heifers. The average mortality rates were 0.5 to 4 times higher when calculated only on farms with at least 1 death (0-excluded) compared with the whole population (0-included). The difference between the 0-included and 0-excluded mortality rates was high, as the percentage of farms with zero mortality was high (beef-crossed calves and heifers, for instance). For beef-crossed calves, the mean mortality rate was of the same order of magnitude as for noncrossed calves when the farms with zero mortality were included (0-included). Large ranges of mortality rates were obtained for each category of animals, as shown by the values of the standard deviation, of the minimum and maximum, and by the fact that the standard deviations were of the same order as the means. For 3-d- to 1-mo-old mortality, the number of calf-months accounted for around 70,75 , and $58 \%$ of the number of calves present at $3 \mathrm{~d}$ of age for all calves, noncrossed calves and beef-crossed calves, respectively. This induced a higher mortality rate when calf-month was used compared with calves present at the first day of the period (Table 2). The effect of the herdsize threshold used to assign the herd to the French average mortality rates reported in Tables 1, 2, and 3 is presented in Table 4. For the whole population (0-included), increasing the herd-size threshold had a low or no effect on the mortality rates calculated with the number of animal-period; it led to an increase in the mortality rates calculated with the number of animals present at birth or at $3 \mathrm{~d}$ of age. On the contrary, increasing the herd-size threshold produced a decrease in the mortality rates for farms with at least one death

Table 1. Mortality rates of 0 - to 2-d-old dairy calves

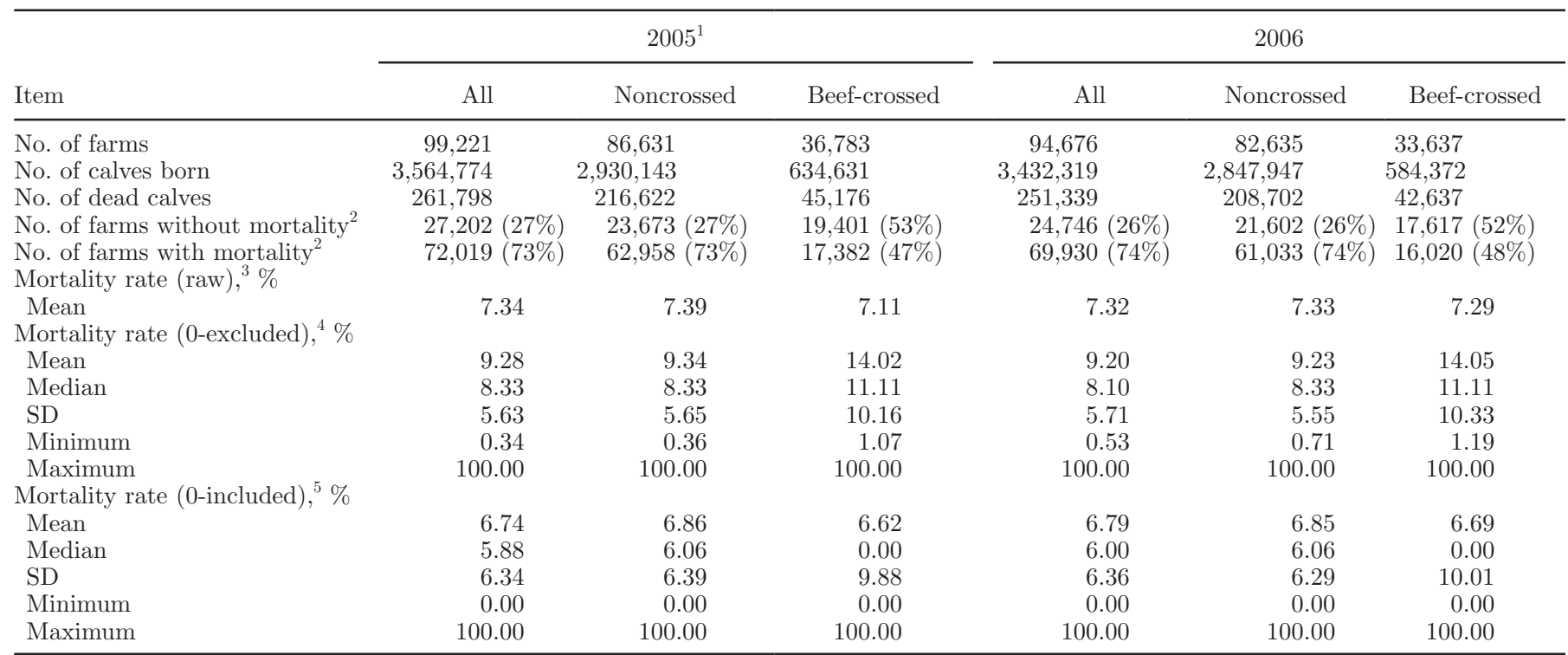

${ }^{1}$ Noncrossed: dairy sire and dam; Beef-crossed: beef sir and dairy dam.

${ }^{2}$ Farms without or with 0- to 2-d-old dairy calf death this year; percentages refer to distributions of farms among these with and without mortality.

${ }^{3}$ Refers to the national overall number of deaths divided by the overall number of births.

${ }^{4}$ Refers to the national mean of the herd-level mortality rates, excluding the farms without mortality; mortality rates are the number of 0 - to 2-d-old dead calves divided by the number of calves born.

${ }^{5}$ Refers to the national mean of the herd-level mortality rates, including all farms; mortality rates are the number of 0 - to 2 -d-old dead calves divided by the number of calves born. 
Table 2. Mortality rates of 3-d- to 1-mo-old dairy calves

\begin{tabular}{ccccccc}
\multicolumn{2}{c}{$2005^{1}$} & & & \multicolumn{2}{c}{2006} \\
\cline { 1 - 2 } \cline { 5 - 6 } All & Noncrossed & Beef-crossed & & All & Noncrossed & Beef-crossed \\
\hline 98,832 & 86,160 & 34,842 & & 94,270 & 82,177 & 31,777 \\
$3,302,976$ & $2,713,521$ & 589,456 & & $3,180,980$ & $2,639,245$ & 541,738 \\
$2,388,069$ & $2,044,520$ & 345,527 & & $2,334,828$ & $2,015,127$ & 319,706 \\
138,913 & 112,021 & 26,892 & & 133,011 & 107,908 & 25,103 \\
$43,523(44 \%)$ & $39,619(46 \%)$ & $23,852(68 \%)$ & & $41,513(44 \%)$ & $37,554(46 \%)$ & $21,906(69 \%)$ \\
$55,309(56 \%)$ & $46,541(54 \%)$ & $10,990(32 \%)$ & & $52,727(56 \%)$ & $44,623(54 \%)$ & $9,871(31 \%)$
\end{tabular}

Mortality rate (raw), ${ }^{3} \%$

Mean

Mortality rate, (0-excluded), ${ }^{4} \%$

Mean

Median

SD

Minimum

Maximum

Mortality rate (0-included) ${ }^{5} \%$

Mean

Median

$\mathrm{SD}$

Minimum

Maximum

Number of deaths on number of calf-mo

\subsection{0}

present during the yr

Mortality rate (raw), ${ }^{3} \%$

Mortality

Mortality rate (0-excluded), ${ }^{4} \%$

Mean

Median

SD

Minimum

Maximum

Mortality rate (0-included), ${ }^{5} \%$

Mean

Median

SD

Minimum

Maximum

$\begin{array}{rrr}4.20 & 4.12 & 4.56 \\ 7.14 & 7.17 & 12.54 \\ 5.45 & 5.55 & 10.00 \\ 5.87 & 5.58 & 10.51 \\ 0.60 & 0.69 & 1.08 \\ 100.00 & 100.00 & 100.00 \\ & & \\ 3.99 & 3.87 & 3.95 \\ 2.31 & 2.22 & 0.00 \\ 5.64 & 5.44 & 8.29 \\ 0.00 & 0.00 & 0.00 \\ 100.00 & 100.00 & 100.00\end{array}$

4.18
7.12
5.35
5.85
0.62
100.00

3.98
2.31
5.63
0.00
100.00

4.08
7.12
5.55
5.53
0.63
90.00

3.86
2.22
5.40
0.00
90.00

4.63

12.60
10.00

11.11
0.95

100.00

3.92

0.00

8.53

0.00
00.00

${ }^{1}$ Noncrossed: dairy sire and dam; Beef-crossed: beef sire and dairy dam.

\begin{tabular}{|c|c|c|c|c|c|}
\hline 5.81 & 5.47 & 7.78 & 5.69 & 5.53 & 7.95 \\
\hline 10.12 & 9.76 & 17.29 & 10.01 & 9.61 & 16.93 \\
\hline 7.57 & 7.38 & 13.51 & 7.38 & 7.24 & 13.35 \\
\hline 8.67 & 8.05 & 13.96 & 8.68 & 7.94 & 13.91 \\
\hline 0.72 & 0.72 & 1.49 & 0.69 & 0.69 & 1.48 \\
\hline 100.00 & 100.00 & 100.00 & 100.00 & 100.00 & 100.00 \\
\hline 5.77 & 5.38 & 5.78 & 5.71 & 5.32 & 5.58 \\
\hline 3.33 & 3.01 & 0.00 & 3.25 & 2.96 & 0.00 \\
\hline 8.20 & 7.70 & 11.48 & 8.22 & 7.60 & 11.29 \\
\hline 0.00 & 0.00 & 0.00 & 0.00 & 0.00 & 0.00 \\
\hline 100.00 & 100.00 & 100.00 & 100.00 & 100.00 & 100.00 \\
\hline
\end{tabular}

${ }^{2}$ Farms without or with 3-d- to 1-mo-old dairy calf death this year; percentages refer to distributions of farms among these with and without mortality.

${ }^{3}$ Refers to the national overall number of deaths divided by the overall number of births.

${ }^{4}$ Refers to the national mean of the herd-level mortality rates, excluding the farms without mortality; mortality rates are the number of 3-d- to 1-mo-old dead calves divided by the number of calves present at $3 \mathrm{~d}$ old (upper part) or the number of 3-d- to 1-mo-old dead calves divided by the number of calf-mo (lower part).

${ }^{5}$ Refers to the national mean of the herd-level mortality rates, including all farms; mortality rates are the number of 3-d- to 1-mo-old dead calves divided by the number of calves present at $3 \mathrm{~d}$ old (upper part) or the number of 3-d- to 1-mo-old dead calves divided by the number of calf-mo (lower part). 
Table 3. Mortality rates of dairy heifers

\begin{tabular}{|c|c|c|c|c|c|c|}
\hline Item & \multicolumn{3}{|c|}{2005} & \multicolumn{3}{|c|}{2006} \\
\hline No. of farms & 71,846 & 72,096 & 67,754 & 69,231 & 69,725 & 62,544 \\
\hline No. of heifer-mo & $1,158,838$ & & & $1,148,323$ & & \\
\hline No. of heifer- 5 mo & & $1,125,546$ & & & $1,121,002$ & \\
\hline No. of farms without mortality ${ }^{1}$ & $43,196(60 \%)$ & $50,067(69 \%)$ & $45,866(68 \%)$ & $41,698(60 \%)$ & $48,006(69 \%)$ & $42,006(67 \%)$ \\
\hline No. of farms with mortality ${ }^{1}$ & $28,650(40 \%)$ & $22,029(31 \%)$ & $21,888(32 \%)$ & $27,533(40 \%)$ & $21,719(31 \%)$ & $20,538(33 \%)$ \\
\hline Mortality rate (raw), ${ }^{2} \%$ & & & & & & \\
\hline Mean & 4.55 & 3.15 & 4.34 & 4.40 & 3.13 & 4.71 \\
\hline Mortality rate (0-excluded), ${ }^{3} \%$ & & & & & & \\
\hline Mean & 11.28 & 10.21 & 12.83 & 10.91 & 10.01 & 13.36 \\
\hline Median & 8.88 & 8.19 & 10.00 & 8.69 & 8.00 & 10.41 \\
\hline Median & 0.00 & 0.00 & 0.00 & 0.00 & 0.00 & 0.00 \\
\hline SD & 7.63 & 6.31 & 8.45 & 7.35 & 6.21 & 8.93 \\
\hline Minimum & 0.00 & 0.00 & 0.00 & 0.00 & 0.00 & 0.00 \\
\hline Maximum & 100.00 & 100.00 & 100.00 & 100.00 & 100.00 & 100.00 \\
\hline
\end{tabular}

${ }^{1}$ Farms without or with dairy heifer death this year; percentages refer to distributions of farms among these with and without mortality.

${ }^{2}$ Refers to the national overall number of deaths divided by the overall number of births.

${ }^{3}$ Refers to the national mean of the herd-level mortality rates, excluding the farms without mortality; mortality rates are the number of dead heifers during the respective period divided by the number of heifer-mo, heifer- 5 mo, or heifer-yr.

${ }^{4}$ Refers to the national mean of the herd-level mortality rates, including all farms; mortality rates are the number of dead heifers during the respective period divided by the number of heifer-mo, heifer- 5 mo, or heifer-yr.

(0-excluded). The effect of calving season is important in France (Figures 1 and 2); dairy calf mortality rates increased during winter and were lower during summer.

The survival probability for dairy calves up to $30 \mathrm{~d}$ of age is shown in Figures 3, 4, and 5. Compared with noncrossed males, the odds ratios [and 95\% confidence interval] for an animal dying were 1.00 [1.00-1.01], 0.83 [0.83-0.84], and 0.79 [0.78-0.79] for beef-crossed males, noncrossed females, and beef-crossed females, respectively (Figure 3 ). The odds ratio of mortality was 1.20 [1.19-1.21] for males compared with females, disregarding the breed cross. The odds ratio of mortality was 0.98 [0.98-0.99] for beef-crossed compared with noncrossed calves, disregarding the sex. For females, the odds ratios of mortality for crossed compared with noncrossed were 0.95 [0.94-0.96] and 1.63 [1.57-1.69], for 0 to $18 \mathrm{~d}$ and 19 to $31 \mathrm{~d}$ of age, respectively. The monthly male mortality always remained higher than the monthly female mortality (Figure 2). Within females or males, the mortality of beef-crossed calves exceeded that of noncrossed calves during the winter mortality peak. On the contrary, mortality in noncrossed calves remained high during the mortality nadir in summer. Compared with noncrossed Holstein calves, the odds ratios of mortality were 1.01 [1.00-1.02] and 0.87 [0.86-0.88] for Normande and Montbéliarde, respectively, disregarding the sex (Figure 4). Compared with area 1, the odds ratios of calf mortality were lower for areas 6 to 9 and 11 and higher for areas 2 to 4 and 10 (Table 5). The survival probability of dairy heifers up to $30 \mathrm{~d}$ of age or up to the first calving is indicated in Figures 5 and 6 . The 0 - to 2-d-old mortality in noncrossed female dairy calves (most of them being heifers) is reported in Figure 3. The Kaplan-Meier curve for all heifers, irrespective of breed, was very close to the Holstein curve (Figure 6, data not shown). The mortality probability was very high for the first days of life (Figures 5 and 6), then decreased during the first year of life and became constant around $3 \mathrm{yr}$ of age (Figure 6). The risk of mortality in heifers calving late $(>3$-yrold) was very low after $3 \mathrm{yr}$ of age and before the first calving, as shown by the slope of the curve during this period. Compared with Holstein heifers, the odds ratios of mortality between birth and first calving were 1.15 [1.14-1.17] and 1.51 [1.49-1.52] for Montbéliarde and Normande, respectively (Figure 6). Compared with area 1 , the odds ratios of heifer mortality were higher for all areas, when significant (Table 5). 
Table 4. Effects of excluding small herds on the mortality rates

\begin{tabular}{|c|c|c|c|c|c|c|}
\hline \multirow[b]{2}{*}{ Item $^{1}$} & \multirow[b]{2}{*}{ Subset } & \multicolumn{5}{|c|}{ Mortality rate, $\%$} \\
\hline & & $>5$ animals & $>10$ animals & $>15$ animals & $>20$ animals & $>30$ animals \\
\hline \multicolumn{7}{|l|}{ 0-2-d-old dairy calves } \\
\hline \multirow{2}{*}{ All } & 0 -included & 6.74 & 6.91 & 7.11 & 7.31 & 7.66 \\
\hline & 0 -excluded & 9.28 & 9.1 & 8.95 & 8.86 & 8.72 \\
\hline \multirow{2}{*}{\multicolumn{7}{|c|}{$\begin{array}{l}\text { 3-d- to } 1 \text {-mo-old dairy calves } \\
\text { (number of calves at } 3 \text {-d-old) }\end{array}$}} \\
\hline & & & & & & \\
\hline \multirow[t]{2}{*}{ All } & 0 -included & 3.99 & 4.01 & 4.06 & 4.12 & 4.31 \\
\hline & 0-excluded & 7.14 & 6.84 & 6.63 & 6.43 & 6.07 \\
\hline Noncrossed & 0 -included & 3.87 & 3.94 & 4.05 & 4.11 & 4.33 \\
\hline \multirow[t]{2}{*}{ All } & 0-included & 5.77 & 5.75 & 5.75 & 5.78 & 5.83 \\
\hline & 0-excluded & 10.12 & 9.41 & 8.88 & 8.33 & 7.57 \\
\hline \multirow[t]{2}{*}{ Noncrossed } & 0 -included & 5.38 & 5.45 & 5.49 & 5.56 & 5.57 \\
\hline & 0-excluded & 9.76 & 9.12 & 8.54 & 8.07 & 7.3 \\
\hline \multirow[t]{2}{*}{ Beef-crossed } & 0 -included & 5.78 & 4.71 & 4.25 & 4.09 & 4.09 \\
\hline & 0 -excluded & 17.29 & 12.1 & 9.69 & 8.4 & 7.17 \\
\hline \multicolumn{7}{|l|}{ Dairy heifers } \\
\hline \multirow[t]{2}{*}{3 -d- to 1-mo-old } & 0-included & 4.49 & 4.41 & 4.41 & 4.68 & 4.54 \\
\hline & 0-excluded & 11.28 & 9.68 & 8.48 & 7.67 & 6.67 \\
\hline \multirow[t]{2}{*}{ 1-6-mo-old } & 0-included & 3.12 & 3.03 & 2.99 & 3.08 & 3.24 \\
\hline & 0-excluded & 10.21 & 8.56 & 7.28 & 6.44 & 5.54 \\
\hline \multirow[t]{2}{*}{ 6-mo-old to calving 1} & 0 -included & 4.14 & 3.54 & 3.37 & 3.27 & 3.27 \\
\hline & 0-excluded & 12.83 & 9.58 & 7.79 & 6.63 & 5.55 \\
\hline
\end{tabular}

${ }^{1}$ Noncrossed: dairy sire and dam; Beef-crossed: beef sire and dairy dam.

\section{DISCUSSION}

\section{Database and Calculation Methods}

The present study did not aim to identify the mortality changes with time, the aim of the 2-year analysis was to demonstrate the robustness of the results. An analysis of calf mortality between 2000 and 2010 was prevented by the outbreak of Blue Tongue Virus 8 that affected cattle births and deaths from 2007 to 2009 (Perrin et al., 2010). The French National Bovine Identification Database represents the whole population of French cattle; recording of data by the farmer is mandatory, and around $2 \%$ of the farms are controlled each year, with financial penalties for inadequate cattle identification or data records (Henke and Sardonne, 2003). Sex or breed errors made by the farmers could be corrected during the first months of life; consequently, the records kept by the farmers are considered to be very accurate.

The number of calves born per herd was low in the present study $($ mean $=36$, standard deviation $=20$ for 2005-2006), and in some herds one or several classes of animals had zero mortality. Consequently, only the mean national mortality rate excluding the zero values should be used for comparison with studies on large herds (Donovan et al., 1998; Bicalho et al., 2007; Lombard et al., 2007; Stull et al., 2008; Gundelach et al., 2009) or carried out in countries with a large average herd-size (Meyer et al., 2000; Silva del Río et al., 2007; Stull et al., 2008). As in the present study, some reports showed zero calf mortality in $12 \%$ of herds (Nielsen et al., 2010), or 237 out of 1,069 farms, with no death up to 2 yr of age (Menzies et al., 1996), suggesting that both results (0-excluded and 0-included) should be presented. Changing the herd-size threshold to include herds in the present analysis had a small effect on the mortality rates for all noncrossed calves and for heifers (Table 4). On the contrary, increasing the thresholds of inclusion would result in the exclusion of a large proportion of French cattle. In 2005 and 2006, the average number of calves born was 30 and 9 calves for noncrossed and beef-crossed calves, respectively. This is in accordance with the large differences in mortality between the different thresholds for beef-crossed calves. 


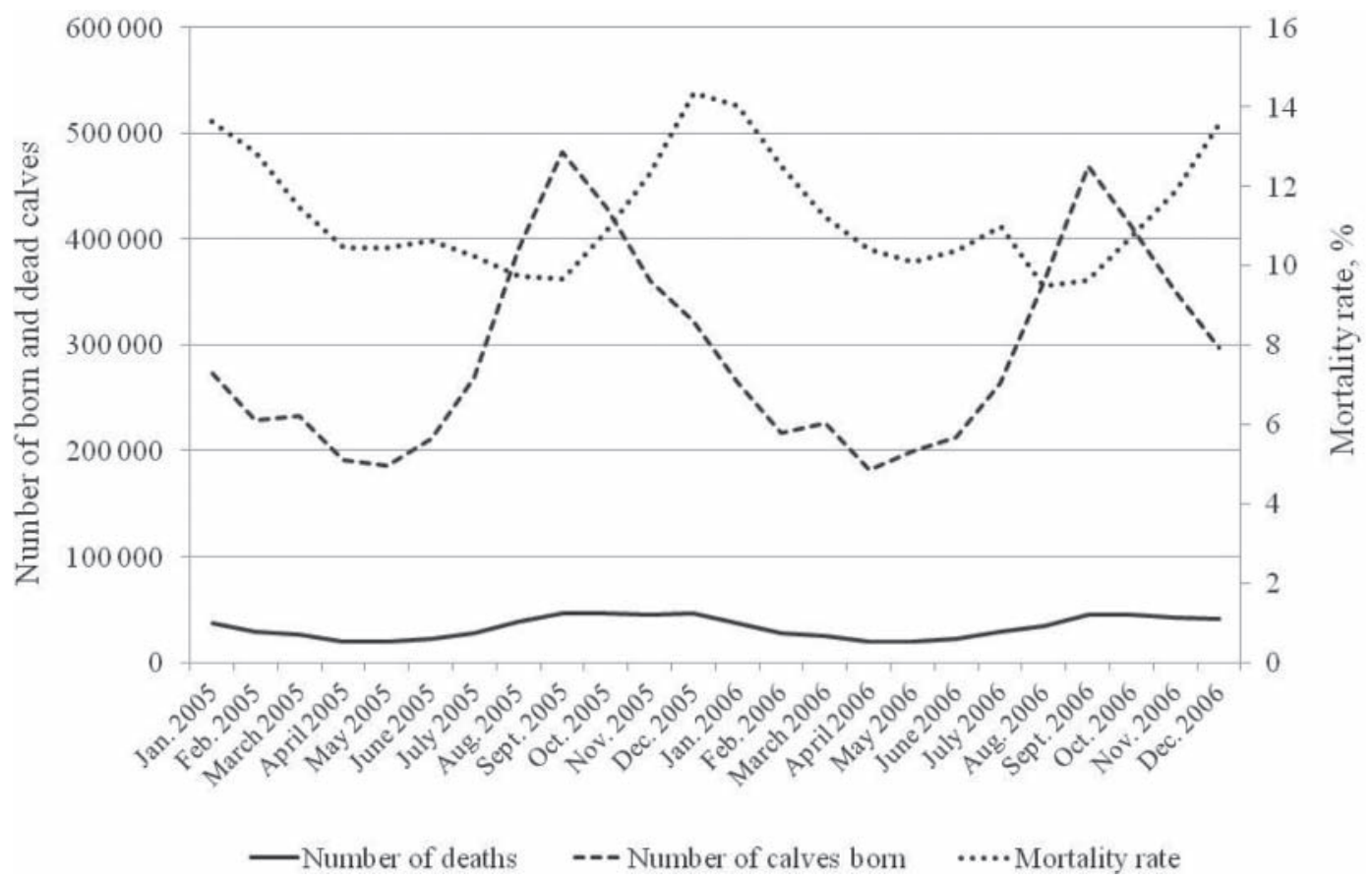

Figure 1. Mortality of calves up to $30 \mathrm{~d}$ of age per month.

Some conflicting results were apparent for the mortality of beef-crossed calves compared with noncrossed calves. The lower odds ratio of mortality for beef-crossed calves compared with noncrossed calves is in opposition with the 0 -excluded results (mortality of beef-crossed calves $>$ noncrossed calves) but in accordance with the 0 -included results (mortality of beef-crossed calves < noncrossed calves; Tables 1 and 2). Moreover, the mortality rate for beef-crossed calves was lower than that of noncrossed calves for both 0 - to 2-d-old calves and

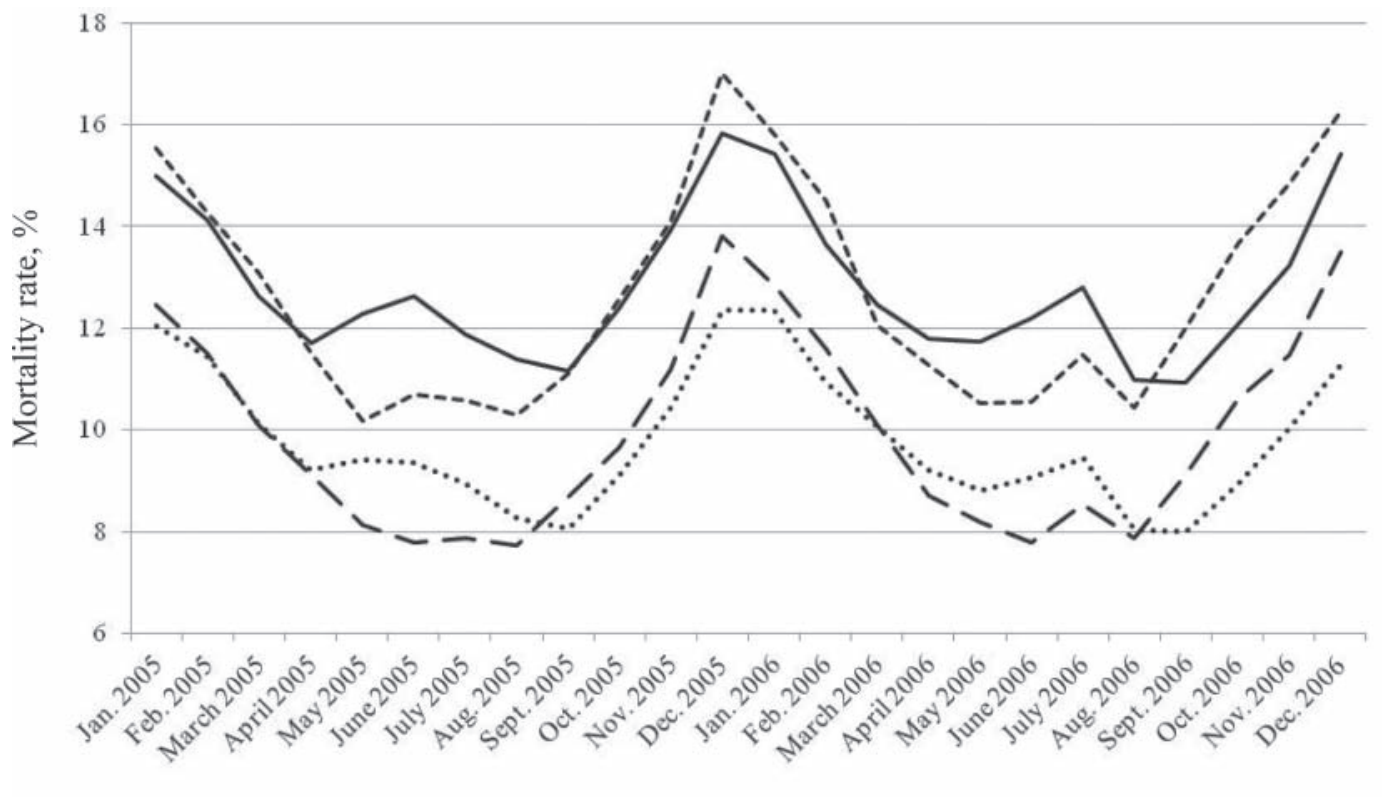

—Males, Non-crossed --- Males, Beef-crossed $\cdots \cdots$ Females, Non-crossed $-\cdot$ Females, Beef-crossed

Figure 2. Mortality of calves up to $30 \mathrm{~d}$ of age per month. 


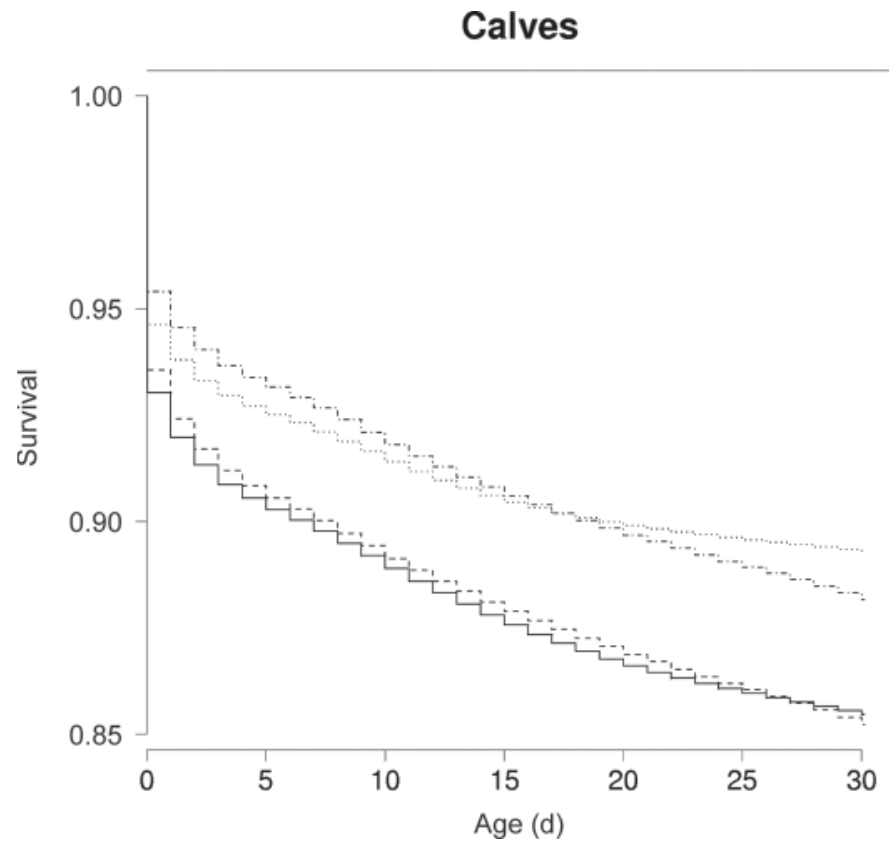

Figure 3. Kaplan-Meier curve of dairy calf mortality up to $30 \mathrm{~d}$ of age by sex and breed. Solid line $=$ male, noncrossed; dotted line $=$ male, beef-crossed; tiny dotted line $=$ female, noncrossed; alternated dotted line $=$ female, beef-crossed.

3-d- to 1-mo-old calves when calculated on large herds only (Table 4). Altogether, this shows that mortality was slightly reduced in beef-crossed compared with noncrossed calves.

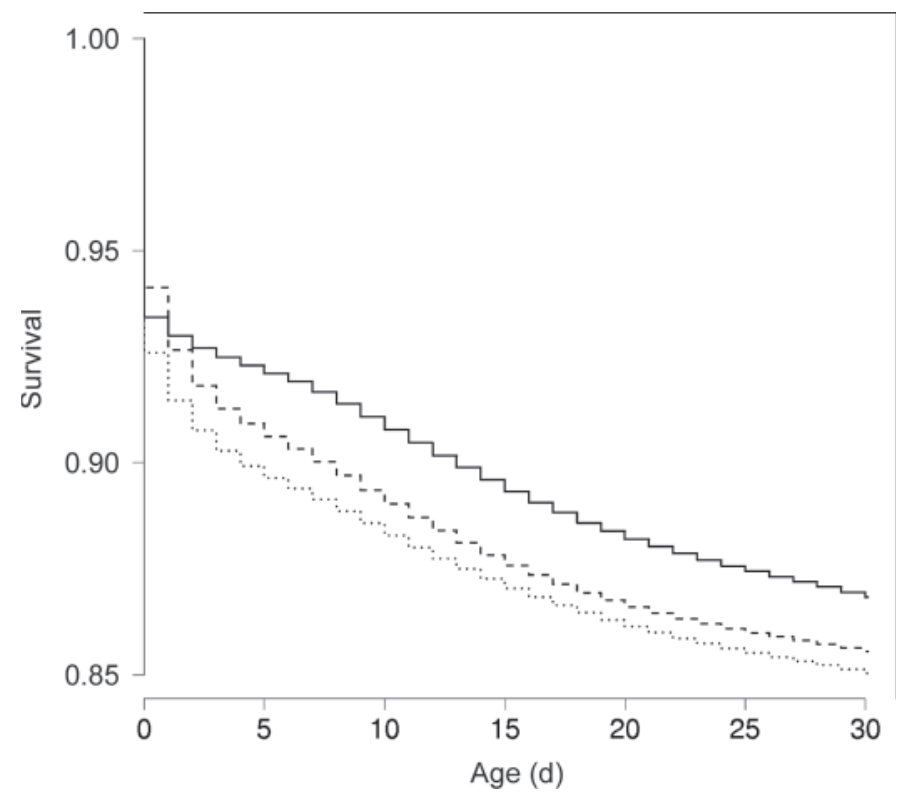

Figure 4. Kaplan-Meier curve of dairy calf mortality up to $30 \mathrm{~d}$ of age for the 3 main breeds. Male and female noncrossed calves are included. Solid line $=$ Montbéliarde; dotted line = Normande; tiny dotted line $=$ Holstein

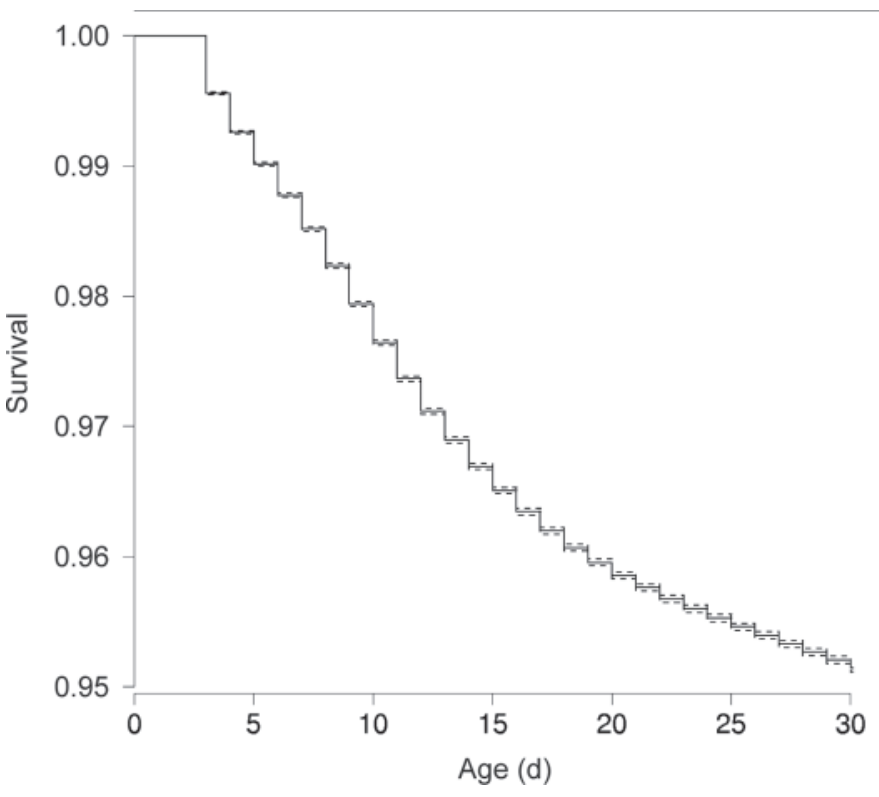

Figure 5. Kaplan-Meier curve of heifer mortality up to $30 \mathrm{~d}$ of age. The solid curve represents the survival function and the dotted line the $95 \%$ CI of the estimation. The survival is calculated with the heifers still present at $2 \mathrm{~d}$ of age.

\section{Main Findings About Perinatal Mortality}

Altogether, this study shows that the French average perinatal (0-2-d-old) mortality rate tends to be within the lower part of the range of values reported for this class of age. The French mortality rate calculated as the overall number of deaths over the number of births was around $7.32 \%$, and the 0 -included mortality rate was around $6.79 \%$. With similar methods of calculation, including stillbirths and deaths up to $48 \mathrm{~h}$ of age, the perinatal mortality reported in the United States for 600,000 and 5,712 births was 7.0 and $8.8 \%$, respectively (Meyer et al., 2000; Johanson et al., 2011). The perinatal mortality, including stillbirths and deaths up to $24 \mathrm{~h}$ of age, varied between 6.5 and $9.7 \%$ in most of the studies. Among the lowest rates, one study performed in the 1990s reported a mortality rate of $6.9 \%$ for 250 calvings, whereas another performed in the 2000 s in the United States reported a mortality rate of $6.5 \%$ for 32,300 births (Bicalho et al., 2007). In another study, the mortality rate for the United States was $8.2 \%$ for 7,380 births (Lombard et al., 2007). Taking into account that the threshold was up to $48 \mathrm{~h}$ of age in the present study, and between 24 and $48 \mathrm{~h}$ in most of the others, the French 0 - to 2-d-old calf mortality rate appears low. This conclusion is reinforced by the perinatal mortality (stillbirths and deaths up to $24 \mathrm{~h}$ ) reported in 2 recent German studies, where the mortality rates were 9.3 and $9.7 \%$ for 13,158 and 483 births, respectively (Gundelach et al., 2009; Hoedemaker et al., 
Table 5. Odds ratios of mortality for the French dairy production areas ${ }^{1}$

\begin{tabular}{lccc}
\hline Item & $\begin{array}{c}\text { Birth to } 1 \text {-mo-old } \\
\text { calves }\end{array}$ & $\begin{array}{c}\text { 3-d- to 1-mo-old } \\
\text { heifers }\end{array}$ & $\begin{array}{c}\text { 6-mo-old to calving } \\
\text { 1 heifers }\end{array}$ \\
\hline 1 (Grand-Ouest) & Reference & Reference & Reference \\
2 (Normandie) & $1.26[1.25-1.27]$ & $1.55[1.52-1.57]$ & $1.54[1.52-1.56]$ \\
3 (Nord) & $1.10[1.09-1.11]$ & $1.27[1.24-1.29]$ & $1.25[1.25-1.27]$ \\
4 (Est) & $1.17[1.16-1.18]$ & $1.36[1.33-1.39]$ & $1.32[1.30-1.34]$ \\
5 (Centre) & $0.96[0.95-1.97]$ & $1.08[1.03-1.13]$ & $1.20[1.17-1.24]$ \\
6 (Poitou) & $0.85[0.84-0.86]$ & $1.00[0.97-1.11]$ & $1.07[1.04-1.09]$ \\
7 (Massif Central) & $0.63[0.62-0.64]$ & $1.07[1.04-1.11]$ & $1.14[1.12-1.17]$ \\
9 (Rhône-Alpes) & $0.70[0.69-0.71]$ & $1.04[1.00-1.07]$ & $1.14[1.12-1.17]$ \\
10 (Franche-Conté) & $0.68[0.67-0.69]$ & $1.13[1.10-1.16]$ & $1.12[1.10-1.14]$ \\
11 (Savoie) & $1.20[1.19-1.21]$ & $1.27[1.24-1.31]$ & $1.19[1.17-1.21]$ \\
\hline
\end{tabular}

${ }^{1} 95 \%$ CI listed in brackets.

2010). On the contrary, results from northern European countries led to the conclusion that perinatal mortality rates were very low (3.4-3.6\%; Olsson et al., 1993; Gulliksen et al., 2009). Nevertheless one of these studies included only stillbirths.

In the present study, the perinatal mortality could include abortions, as well as some deaths after $48 \mathrm{~h}$ of age. In a recent study on 57 French beef farms (Briens, 2011), a recorded date of death 2 to $3 \mathrm{~d}$ after the true date of death was reported for $50 \%$ of calves and the same date of birth and death was recorded for some calves even if they died a few days after birth (independently of the recording date). Some calves may have been inaccurately assigned to the 0 - to 2-d-old or the

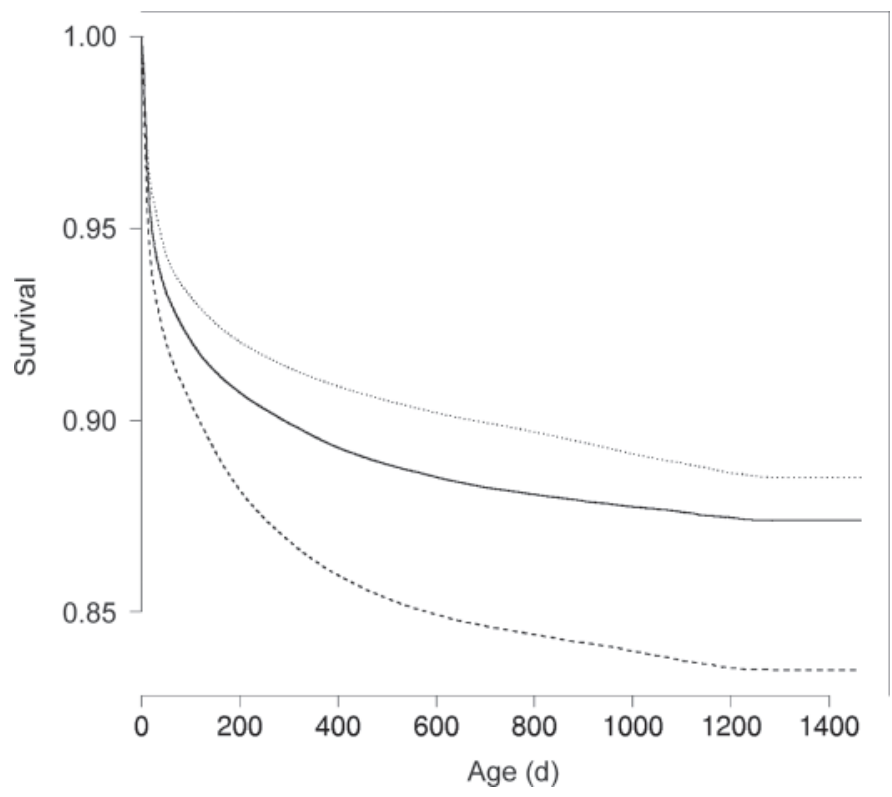

Figure 6. Kaplan-Meier curve of heifer mortality up to the first calving for the 3 main breeds. The survival is calculated with the heifers still present at $2 \mathrm{~d}$ of age. Solid line $=$ Montbéliarde; dotted line $=$ Normande; tiny dotted line $=$ Holstein . 3-d- to 1-mo-old classes in the present study. If biases resulting from abortion or deaths after $48 \mathrm{~h}$ of age occurred here, they would lead to an overestimation of the perinatal mortality and would consequently be in accordance with the low dairy perinatal mortality in France in 2005 and 2006.

\section{Main Findings About Neonatal Mortality}

Neonatal mortality was here defined as between $3 \mathrm{~d}$ and 1 mo of age; this definition seems consensual (Heinrichs and Radostits, 2001). In the present study, the 3 -d- to 1-mo-old mortality rate calculated as the overall number of deaths divided by the number of births was around $4.20 \%$, and the 0 -included mortality rate (with number of calves present at $3 \mathrm{~d}$ old as the denominator) was around $3.99 \%$ (Table 2). To our knowledge, this is the first description of neonatal mortality among dairy calves. Comparison with previously published results is difficult because of differences in calculation methods; mortality is often reported up to 90 or $180 \mathrm{~d}$ of age, and the inclusion of males or females in some studies is unclear. Among 4,839 births in Sweden, mortality was 2.6 and $0.7 \%$ for the 0 to $90-\mathrm{d}$ period (excluding stillbirth) and the 1 to 7 -d period, respectively (Olsson et al., 1993). In Denmark, a mortality rate of $7.0 \%$ was reported between birth (excluding stillbirth) and 6 mo of age (Nielsen et al., 2010). Among 4,097 live-born Iranian calves, $6.5 \%$ died within $90 \mathrm{~d}$ (Azizzadeh et al., 2012). In a US trial conducted in the 1970 s, the 0 to 15 and 15 to 60 -d mortality rates were 8.5 and $2.8 \%$, respectively (Oxender et al., 1973). Recently, 4.6\% of live-born US calves died before $135 \mathrm{~d}$ of life in a survey of 1,138 births (Linden et al., 2009). The lower neonatal mortality compared with the perinatal mortality reported in the present study remains in accordance with previous studies (Oxender et al., 1973; Olsson et al., 1993). 
In the present study, the neonatal mortality based on the number of calf-month and the Kaplan Meier curves excluded calves sold (mainly to veal-calf operations) before $30 \mathrm{~d}$ of age, as the risks of disease and mortality are known to be higher in transported and commingled calves. For instance, inclusion of all the farms would lead to an additional 4.0 (2005) and 4.8\% (2006) noncrossed dairy calves dying between birth and 1-mo-old, compared with the 328,643 (2005) and 316,610 (2006) calves that died in the present study (Tables 1 and 2). Consequently, the nonbias mortality rate using the number of calf-months is useful for a rigorous comparison between studies and for variance analysis, as suggested by the differences between results noted with the 2 methods (Table 2). The selling age of calves differed considerably between countries and areas. On the contrary, taking the animals present at the first day of the analyzed period into consideration, calves sold during that period were considered at risk throughout the entire period. Although this method of calculation is biased, it is still used in the field and advisors may refer to these results.

The reduction of neonatal mortality remains an important economic and animal welfare challenge for the dairy and fattening industry. Although not directly evaluated, the relationship between mortality and gastro-intestinal morbidity in the present study was probably high. Gastrointestinal conditions are the main diseases leading to death during the neonatal period. Gastrointestinal disorders, or septicemia, were detected in 66 (Menzies et al., 1996), 43 (Svensson et al., 2006), or $45 \%$ (Agerholm et al., 1993) of dead calves during necropsy. Grouping males and females to obtain a single mortality rate is suggested because the calves are subjected to the same housing and breeding conditions up to departure of the males.

\section{Main Findings About Dairy Heifer Mortality}

Altogether, the dairy heifer mortality from 3-d-old to first calving appears at the lowest part of the range reported from international studies. In the 2000s, the annual heifer mortality was 7.8 and $1.8 \%$ for US unweaned (>3-d-old) and weaned heifers, respectively (USDA, 2007). All other studies were performed in the 1990s. In a study on 12,300 US heifers, the birth to $7 \mathrm{~d}$ and birth to $64 \mathrm{~d}$ mortality rates were 1.9 and $6.3 \%$, respectively (Wells et al., 1997). The birth to 90 $\mathrm{d}$ and birth to $100 \mathrm{~d}$ mortality rates were 5.6 and $6.1 \%$, respectively, in 2 US studies (Rea et al., 1996; Virtala et al., 1996). The highest reported value for heifer mortality rate was $11.7 \%$ among 3,103 animals, but the study period included the first 6 mo of life and excluded stillbirth (Donovan et al., 1998). In the present study, the mortality rates calculated as the overall number of deaths over the mean number of animals were around $4.4,3.2$, and $4.5 \%$, and the 0 -included mortality rates were around $4.4,3.1$, and $4.2 \%$, for 3 -d- to 1 -mo-old, 1- to 6-mo-old, and 6-mo-old to first calving heifers, respectively (Table 3). Contrary to previous results (USDA, 2007), no tendency for mortality to decrease was observed in old as compared with young heifers in France.

In the present work, the number of heifer-months, heifer-5-months, or heifer-years is equivalent to the mean number of animals per year or to the average number of animals for a given day. All heifers stay within a French dairy herd and most of them remain within the same herd from birth to first calving (change of herd for less than $2 \%$ of heifers, data not shown). Indeed the methods generally used to calculate the cumulative incidence of mortality in the literature and mortality in the present study are very similar.

The 3 classes of age used here were chosen to represent the main life phases of replacement heifers. From $3 \mathrm{~d}$ to 1 mo of age, males and heifers are bred under the same husbandry conditions up to departure of the males. However, as some individual management practices may differ between the sexes, a separate analysis for heifers seemed appropriate. The second period was from 1 to 6 mo of age, as previously suggested (Donovan et al., 1998; Gulliksen et al., 2009); although this is longer than in other reports where the weaning age or a threshold at 60,90 , or $100 \mathrm{~d}$ of age was used (Rea et al., 1996; Virtala et al., 1996; Wells et al., 1996; USDA, 2007). The main health issues leading to mortality between 1 and 6 mo of age are respiratory diseases and digestive disorders; these represent around 40 to $47 \%$ and 17 to $22 \%$ of the causes of death, respectively (Menzies et al., 1996; Svensson et al., 2006). Moreover, the odds ratios of mortality between 1 and 6 mo of age are 6.21 and 5.58 for respiratory diseases and diarrhea, respectively (Gulliksen et al., 2009). The 6 -mo-old to first calving mortality represents the third part of replacement heifer rearing, where mortality is highly linked to respiratory problems (Menzies et al., 1996; Gulliksen et al., 2009).

\section{Mortality per Season and Sex}

The increased 0 to $30-\mathrm{d}$ mortality rate during winter is in accordance with previous results for perinatal mortality (Johanson et al., 2011) and mortality up to $120 \mathrm{~d}$ of age (Lombard et al., 2007), but in opposition (mortality peak in summer) with others (Azizzadeh et al., 2012). A U-shaped relationship between calf monthly mortality and the monthly average daily temperature was reported, with high mortality occurring 
during periods of low or high temperature (Stull et al., 2008), or during winter and summer (Martin et al., 1975). In France, the coldest winter months are December to February (monthly average daily temperatures between $2-5^{\circ} \mathrm{C}$ for $2005-2006$, data not shown). The mortality peaks noted in June 2005 and July 2006 for some calf classes (Figures 2 and 3) are in accordance with the high monthly average daily temperatures (between $19.0-23.0^{\circ} \mathrm{C}$, data not shown). In addition to the weather, the increased infectious pressure could contribute to the increased dairy calf mortality in winter. This is suggested by the fact that the mortality increase began in October (for both years), after the annual calving peak of September, even though the monthly mean daily temperatures were of the same order (17 and $14^{\circ} \mathrm{C}$ for September and October, respectively). It is also suggested by the parallelism of the birth curve and the mortality rate curve after both peaks (Figure 1). A distinction between the effects related to infectious pressure and to the winter weather conditions cannot be made here.

The higher mortality for males compared with females up to 1 mo (Figures 2 and 3), for all calves compared with heifers for the 3 -d to 1-mo period (Tables 2 and 3), and for noncrossed males compared with noncrossed females after 2-d-old (difference in the slope of the curves, Figure 3 ) are in accordance with previous results. A higher risk of perinatal mortality has been reported for males (Gulliksen et al., 2009; Hoedemaker et al., 2010; Johanson et al., 2011), probably related to the higher mortality associated with concomitant dystocia (Chassagne et al., 1999; Meyer et al., 2001; Johanson et al., 2011) in particular for heavy birth weight (Gundelach et al., 2009; Linden et al., 2009). A higher neonatal mortality for males was also previously reported (Gulliksen et al., 2009). The differential price of males and females (Dematawewa and Berger, 1997) could also contribute to the higher mortality rate for noncrossed males compared with heifers (Tables 2 and 3 ), in addition to the higher biological risk of mortality for males.

\section{Some Farmers Achieve Low to Very Low Mortality Rates}

Even though some farmers and their advisors consider mortality as inescapable, and despite the increased mortality rate in dairy calves and heifers (Meyer et al., 2001), low mortality can be achieved. Zero mortality or low mortality rate were observed in one or several classes of animals on a large percentage of French farms, in accordance with the very high standard deviations. Moreover, other results in the present study show that some farmers were able to reduce dairy calf mortality.
First, because the risk of disease and death is suspected to be higher in beef-crossed calves (increased dystocia, heavier calves and greater growth) compared with noncrossed calves, the opposite results obtained for the 0 to 2-d-old mortality (Table 1 and Figure 3 ) and during the summer mortality peak (Figure 2) are probably linked to specific farmer's management of beef-crossed calves. Second, the higher mortality rates for 0 to 30 -d-old Holstein calves (Figure 4) and the lower mortality rates for 0 to 30-d-old Holstein heifers (Figure 6), compared with Montbéliarde and Normande, suggest differences in management between the sexes and breeds. Third, dairy production area 1 has one of the highest risk of dairy calf mortality but the lowest dairy heifer mortality (Table 5) and the lowest dairy cow mortality (Raboisson et al., 2011). Altogether, these results show that some farmers are able to achieve low calf mortality, even in some classes of animals known to have a high biological risk of mortality. These differences could be related to the farmer's specific management of calving and rearing, but further research is needed to validate this hypothesis.

\section{CONCLUSIONS}

This study revealed low to moderate mortality rates for French dairy calves and heifers compared with international results. The risk of mortality from birth to 1 mo of age was higher during winter and for males compared with females. Mortality was lower for beefcrossed compared with noncrossed calves during the first days of life. The results also clearly demonstrated that some farmers achieve very low mortality rates under given conditions, even in classes of animals known to have a high risk of mortality.

\section{ACKNOWLEDGMENTS}

The authors thank Pascal Deriu (Information Systems, French Ministry of Agriculture, Paris, France) for data disposal and Roland Chartier and Benoit Garcia (INRA, Toulouse, France) for data management support.

\section{REFERENCES}

Agerholm, J. S., A. Basse, H. V. Krogh, K. Christensen, and L. Ronsholt. 1993. Abortion and calf mortality in Danish cattle herds. Acta Vet. Scand. 34:371-377.

Azizzadeh, M., H. F. Shooroki, A. S. Kamalabadi, and M. A. Stevenson. 2012. Factors affecting calf mortality in Iranian Holstein dairy herds. Prev. Vet. Med. 104:335-340.

Berglund, B., L. Steinbock, and M. Elvander. 2003. Causes of stillbirth and time of death in Swedish Holstein calves examined post mortem. Acta Vet. Scand. 44:111-120.

Bicalho, R. C., K. N. Galvao, S. H. Cheong, R. O. Gilbert, L. D. Warnick, and C. L. Guard. 2007. Effect of stillbirths on dam survival 
and reproduction performance in Holstein dairy cows. J. Dairy Sci. 90:2797-2803.

Briens, L. 2011. Description of calf birth and death reporting practices in 57 french suckler herds. In Memoire de fin d'études. ENITA Bordeaux, France.

Chassagne, M., J. Barnouin, and J. P. Chacornac. 1999. Risk factors for stillbirth in Holstein heifers under field conditions in France: A prospective survey. Theriogenology 51:1477-1488.

Dematawewa, C. M., and P. J. Berger. 1997. Effect of dystocia on yield, fertility, and cow losses and an economic evaluation of dystocia scores for Holsteins. J. Dairy Sci. 80:754-761.

Donovan, G. A., I. R. Dohoo, D. M. Montgomery, and F. L. Bennett. 1998. Associations between passive immunity and morbidity and mortality in dairy heifers in Florida, USA. Prev. Vet. Med. 34:31-46.

Gulliksen, S. M., K. I. Lie, T. Loken, and O. Osteras. 2009. Calf mortality in Norwegian dairy herds. J. Dairy Sci. 92:2782-2795.

Gundelach, Y., K. Essmeyer, M. K. Teltscher, and M. Hoedemaker 2009. Risk factors for perinatal mortality in dairy cattle: Cow and foetal factors, calving process. Theriogenology 71:901-909.

Heinrichs, A. J., and O. Radostits. 2001. Health and production management of dairy calves and replacement heifers. In Herd Health Food Animal Production Medicine. O. Radostits, ed. W. B. Saunders Co., Philadelphia, PA.

Henke, R., and R. Sardonne. 2003. The reorientation process of the CAP support: Modulation of direct payments. Pages 93-106 in Role of Institutions in Rural Policies and Agricultural Markets. van Huylenbroeck, G., W. Verbeke, and L. Lauwers, ed. Elsevier, Amsterdam, the Netherlands.

Hoedemaker, M., I. Ruddat, M. Telscher, K. Essmeyer, and L. Kreinbrock. 2010. Influence of animal, herd and management factors on perinatal mortality in dairy cattle-A survey in Thuringia, Germany. Berl. Munch. Tierarztl. Wochenschr. 123:130-136.

Johanson, J. M., P. J. Berger, S. Tsuruta, and I. Misztal. 2011. A Bayesian threshold-linear model evaluation of perinatal mortality, dystocia, birth weight, and gestation length in a Holstein herd. J. Dairy Sci. 94:450-460.

Linden, T. C., R. C. Bicalho, and D. V. Nydam. 2009. Calf birth weight and its association with calf and cow survivability, disease incidence, reproductive performance, and milk production. J. Dairy Sci. 92:2580-2588.

Lombard, J. E., F. B. Garry, S. M. Tomlinson, and L. P. Garber. 2007. Impacts of dystocia on health and survival of dairy calves. J. Dairy Sci. 90:1751-1760.

Martin, S. W., C. W. Schwabe, and C. E. Franti. 1975. Dairy calf mortality rate: The association of daily meteorological factors and calf mortality. Can. J. Comp. Med. 39:377-388.

Menzies, F. D., D. G. Bryson, T. McCallion, and D. I. Matthews 1996. Mortality in cattle up to two years old in Northern Ireland during 1992. Vet. Rec. 138:618-622.

Meyer, C. L., P. J. Berger, and K. J. Koehler. 2000. Interactions among factors affecting stillbirths in Holstein cattle in the United States. J. Dairy Sci. 83:2657-2663.

Meyer, C. L., P. J. Berger, K. J. Koehler, J. R. Thompson, and C. G. Sattler. 2001. Phenotypic trends in incidence of stillbirth for Holsteins in the United States. J. Dairy Sci. 84:515-523.
Nielsen, T. D., L. R. Nielsen, N. Toft, and H. Houe. 2010. Association between bulk-tank milk Salmonella antibody level and high calf mortality in Danish dairy herds. J. Dairy Sci. 93:304-310.

Olsson, S. O., S. Viring, U. Emanuelsson, and S. O. Jacobsson. 1993. Calf diseases and mortality in Swedish dairy herds. Acta Vet. Scand. 34:263-269.

Ortiz-Pelaez, A., D. G. Pritchard, D. U. Pfeiffer, E. Jones, P. Honeyman, and J. J. Mawdsley. 2008. Calf mortality as a welfare indicator on British cattle farms. Vet. J. 176:177-181.

Oxender, W. D., L. E. Newman, and D. A. Morrow. 1973. Factors influencing dairy calf mortality in Michigan. J. Am. Vet. Med. Assoc. 162:458-460.

Perrin, J. B., C. Ducrot, J. L. Vinard, E. Morignat, A. Gauffier, D. Calavas, and P. Hendrikx. 2010. Using the National Cattle Register to estimate the excess mortality during an epidemic: Application to an outbreak of Bluetongue serotype 8. Epidemics 2:207-214.

Raboisson, D., E. Cahuzac, P. Sans, and G. Allaire. 2011. Herd-level and contextual factors influencing dairy cow mortality in France in 2005 and 2006. J. Dairy Sci. 94:1790-1803.

Rea, D. E., J. W. Tyler, D. D. Hancock, T. E. Besser, L. Wilson, D. S. Krytenberg, and S. G. Sanders. 1996. Prediction of calf mortality by use of tests for passive transfer of colostral immunoglobulin. J. Am. Vet. Med. Assoc. 208:2047-2049.

Sarzeaud, P., F. Bécherel, and C. Perrot. 2008. Impact of CAP reform on the evolution of beef production and beef farming system in Europe: Synthesis. Pages 111-118 in EU Beef Farming Systems and CAP Regulations. P. Sarzeaud, ed. EAAP Technical Series, Paris, France.

Silva del Río, N., S. Stewart, P. Rapnicki, Y. M. Chang, and P. M. Fricke. 2007. An observational analysis of twin births, calf sex ratio, and calf mortality in Holstein dairy cattle. J. Dairy Sci. 90:1255-1264.

Steinbock, L., A. Nasholm, B. Berglund, K. Johansson, and J. Philipsson. 2003. Genetic effects on stillbirth and calving difficulty in Swedish Holsteins at first and second calving. J. Dairy Sci $86: 2228-2235$.

Stull, C. L., V. M. L. L. Mc, C. A. Collar, N. G. Peterson, A. R. Castillo, B. A. Reed, K. L. Andersen, and W. R. VerBoort. 2008. Precipitation and temperature effects on mortality and lactation parameters of dairy cattle in California. J. Dairy Sci. 91:4579-4591.

Svensson, C., A. Linder, and S. O. Olsson. 2006. Mortality in Swedish dairy calves and replacement heifers. J. Dairy Sci. 89:4769-4777.

USDA. 2007. Dairy 2007, Part 1: Reference of Dairy Cattle Health and Management Practices in the United States, 2007. USDA-APHISVS, CEAH, Fort Collins, CO.

Virtala, A. M., G. D. Mechor, Y. T. Grohn, and H. N. Erb. 1996. Morbidity from nonrespiratory diseases and mortality in dairy heifers during the first three months of life. J. Am. Vet. Med. Assoc. 208:2043-2046.

Wells, S. J., D. A. Dartgatz, and S. L. Ott. 1996. Factors associated with mortality to 21 days of life in dairy heifers in the United States. Prev. Vet. Med. 29:9-19.

Wells, S. J., L. P. Garber, and G. W. Hill. 1997. Health status of preweaned dairy heifers in the United States. Prev. Vet. Med. 29:185-199. 